\title{
Otic Placodes
}

National Cancer Institute

\section{Source}

National Cancer Institute. Otic Placodes. NCI Thesaurus. Code C34239.

A patch of thickened ectoderm alongside the hindbrain in the early embryo that will give rise to the otic pit. 